\title{
Analysis and Design of Two-Transformer Asymmetrical Half-Bridge Converter
}

\author{
Yi-Hsin Leu and Chern-Lin Chen, Senior Member, IEEE \\ Graduate Institute of Electronics Engineering \& Department of Electrical Engineering \\ National Taiwan University, Taipei, Taiwan 106
}

\begin{abstract}
In this paper, the analysis of steady-state characteristics for two-transformer asymmetrical half-bridge converter is presented. Based on the mathematical derivations, ZVS condition of the power switches is quantized and a design procedure can be developed accordingly. The experimental results obtained from a $200 \mathrm{kHz} 24 \mathrm{~V} / 10 \mathrm{~A}$ prototype converter with $92 \%$ efficiency are used to verify the analytical derivations.
\end{abstract}

\section{I . INTRODUCTION}

The asymmetrical duty cycle control method has been explored in detail for half-bridge flyback and forward topologies due to their inherent soft-switching phenomenon, low switch voltage stress, and high frequency operation [1]-[4]. The control method offers a manner of minimizing the turn on losses of the power switches by recycling the transformer leakage energy and subsequent reduction of the voltage and current surge of the output rectifiers. In single output applications, the asymmetrical half-bridge forward converter is superior to asymmetrical half-bridge flyback converter for its lower root-mean-square current of the output rectifiers. But, the converter is not suitable for operating within a wide input voltage range because the maximum allowable duty cycle is $50 \%$.

A two-transformer asymmetrical half-bridge converter extending the allowable duty cycle to above 0.5 has been presented [5]. The simplified circuit of the converter is shown in Fig. 1. By tuning the different turn ratios of the transformers $T_{1}$ and $T_{2}$, not only the maximum allowable duty cycle can be increased, but also the reverse voltage across the output rectifiers are more balanced [5]-[6]. In practical implementation, converter efficiency and soft-switching phenomena are greatly affected by the circuit parameters. In order to obtain the feasible circuit parameters, thorough analysis of the converter should be conducted.

This paper presents the complete design-oriented analysis of the two-transformer asymmetrical half-bridge converter. The converter operations are analyzed stagewise, and the characteristics of the key components are mathematically derived. Based on the derivative results, the ZVS condition of the power switches is quantized and a design procedure can be developed accordingly. Finally, a $24 \mathrm{~V} / 10 \mathrm{~A}$ prototype converter operating at $200 \mathrm{kHz}$ is then built to verify the analytical derivations.

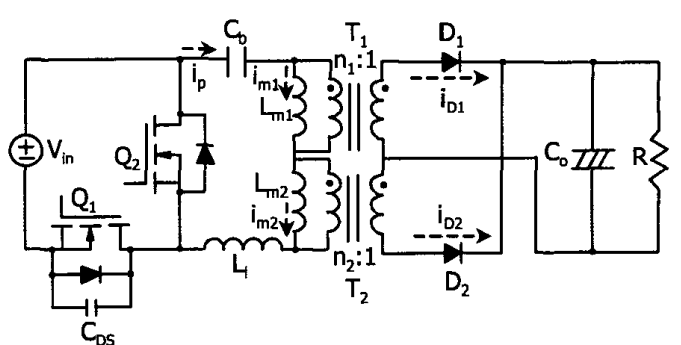

Fig. 1. Simplified schematic of the two-transformer asymmetrical half-bridge converter

\section{PRINCIPLE OF OPERATION}

Referring to Fig. 1, the power switches are driven with asymmetrical duty cycle. The inductor $L_{l}$ represents the leakage inductor, which includes the leakage inductor of $T_{l}$ and $T_{2}$. The capacitor $C_{D S}$ represents the equivalent loop capacitor, which is the combination of the junction capacitor of the switches and the transformer intra winding capacitors. For simplifying the analysis of circuit operation, the following assumptions are made:

- the converter has reached a steady-state operation,

- sufficient energy is stored in $L_{l}$ to completely discharge $C_{D S}$,

- $C_{b}$ is large enough so that the voltage variation of the capacitor is neglected, and

- forward voltage drop of the output rectifier is neglected.

In a switching period, operation of the studied converter can be divided into eight stages. Fig. 2 shows the switching topological states of the converter. The thick solid lines denote the conducting paths for each state. The corresponding waveforms on the key components are given in Fig. 3.

In order to show the transient phenomena clearly, the length of the time intervals $t_{1} \sim t_{3}$ and $t_{5} \sim t_{7}$ have been exaggerated.

Stage $1\left(\mathrm{t}_{0} \sim \mathrm{t}_{1}\right):$ At $\mathrm{t}_{0}$, switch $Q_{1}$ is turned on, and switch $Q_{2}$ is turned off. The voltage across $L_{M 1}$ is clamped at $N_{1} V_{O}$, and the voltage across $L_{M 2}$ can be approximated as $V_{\text {in }}-V_{C}-N_{1} V_{O} . \quad T_{1}$ transfers energy to output through $D_{l}$, and $T_{2}$ works as an inductor.

Stage $2\left(\mathrm{t}_{1} \sim \mathrm{t}_{2}\right):$ After $Q_{1}$ turned off at $\mathrm{t}_{1}, C_{D S}$ is charged by the primary current $i_{p}$. Because $C_{D S}$ is very small, the actual resonant charging manner is approximated as a linear charging characteristic. The voltage across $Q_{1}\left(V_{D S}\right)$ and $L_{M 2}$ is linearly increasing and decreasing, respectively. 

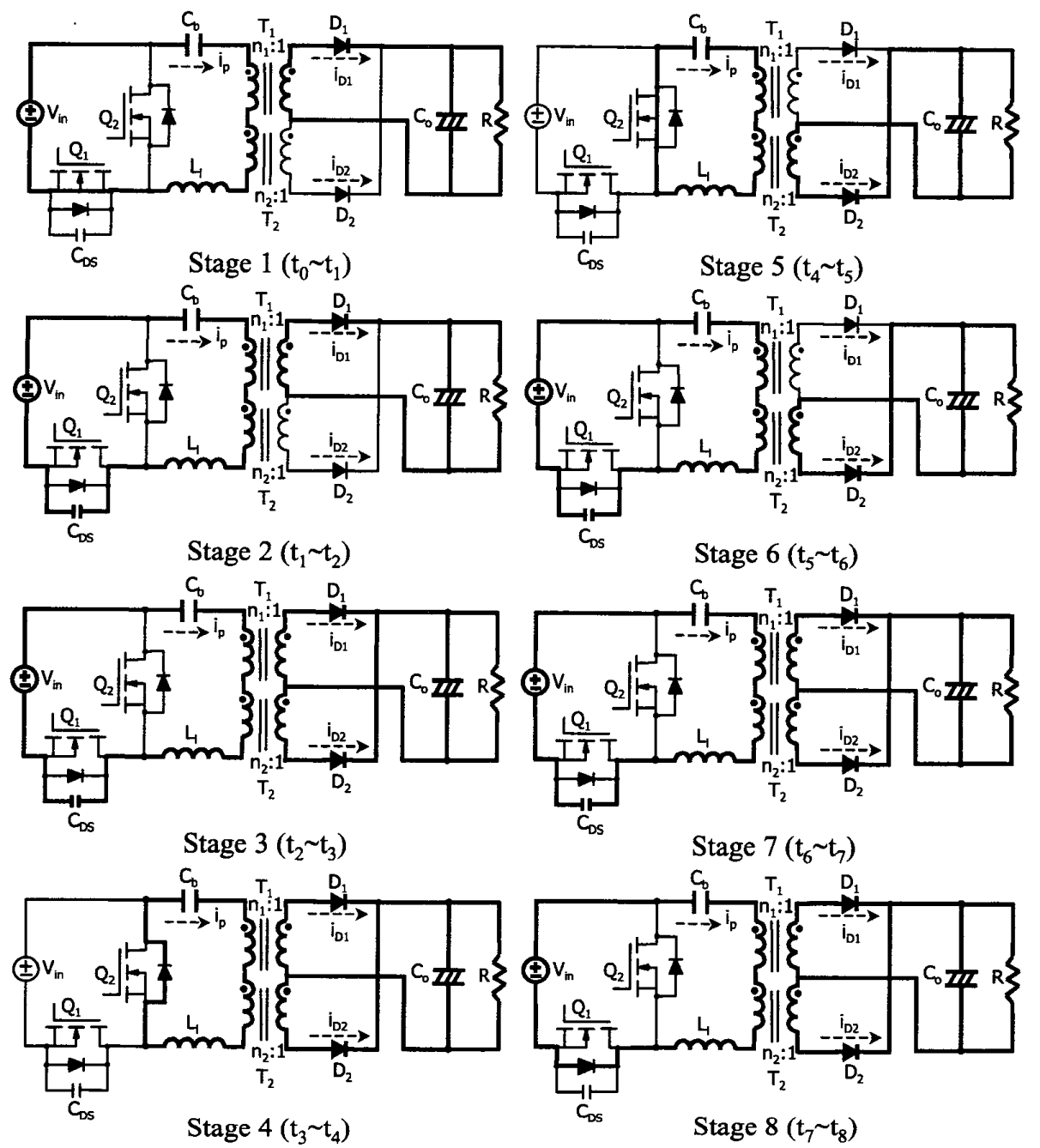

Fig. 2. Eight operational stages of the two-transformer asymmetrical half-bridge converter

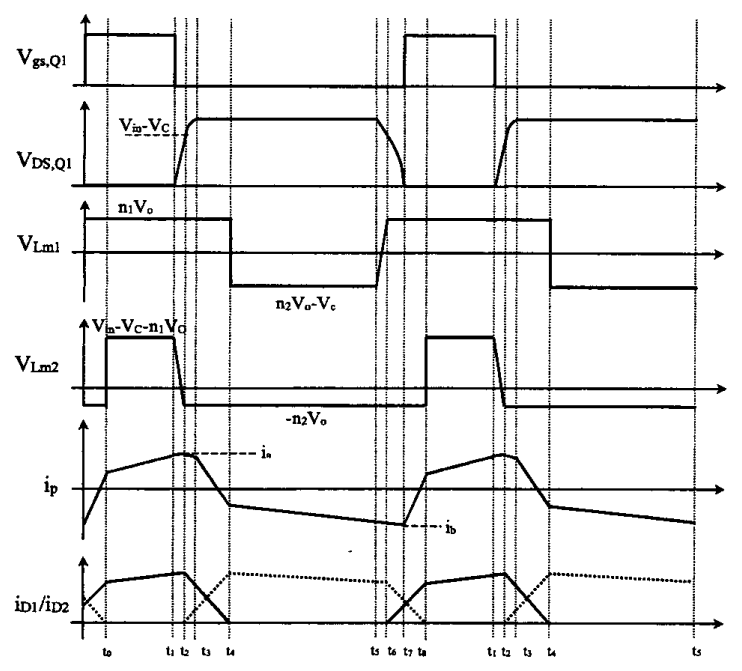

Fig. 3. The theoretical voltage and current waveforms on some key components
Stage $3\left(\mathrm{t}_{2} \sim \mathrm{t}_{3}\right)$ : At $\mathrm{t}_{2}, V_{D S}$ has increased to the point ( $V_{D S}$ $\left.=V_{i n}-V_{C}+N_{2} V_{O}-N_{1} V_{O}\right)$ where the secondary voltage of transformer $T_{2}$ is sufficient to forward bias $D_{2}$. The output rectifiers conduct simultaneously. $L_{l}$ and $C_{D S}$ begin to resonate. The voltage $V_{D S}(t)$ and the primary current $i_{p}(t)$ are expressed by:

$$
\begin{aligned}
& i_{P}(t)=i_{a} \cdot \cos \left[\omega_{r}\left(t-t_{2}\right)\right] \\
& V_{D S}(t)=\left[V_{\text {in }}-V_{C}+\left(N_{2}-N_{1}\right) V_{o}\right]+i_{a} \cdot Z_{r} \cdot \sin \left[\omega_{r}\left(t-t_{2}\right)\right]
\end{aligned}
$$

where, $\omega_{r}=1 / \sqrt{L_{l} \cdot C_{D S}}, Z_{r}=\sqrt{L_{l} / C_{D S}}$

This stage ends when the voltage $V_{D S}$ increases to $V_{i n}$.

Stage $4\left(\mathrm{t}_{3} \sim \mathrm{t}_{4}\right):$ At $\mathrm{t}_{3}, C_{D S}$ is charged to the point $\left(V_{D S}=\right.$ $V_{\text {in }}$ ) where the anti-parallel diode of $Q_{2}$ starts to conduct. In order for $Q_{2}$ to achieve ZVS, the device should be turned on before the primary current $i_{p}$ reverses direction. The primary current $i_{p}$ is ramped down linearly due to the 
negative voltage- $V_{C}+\left(N_{2}-N_{l}\right) V_{O}$ on the leakage inductor.

Stage $5\left(\mathrm{t}_{4} \sim \mathrm{t}_{5}\right)$ : When $i_{p}$ reaches $i_{m l}{ }^{+}$, the diode $D_{1}$ turns off. $T_{2}$ delivers power to output through $D_{2}$, and $T_{1}$ plays an inductor role. The primary current $i_{p}$ decreases linearly with the slope $\left(\mathrm{N}_{2} V_{O^{-}} V_{C}\right) / L_{l}$.

Stage $6\left(\mathrm{t}_{5} \sim \mathrm{t}_{6}\right)$ : After $Q_{2}$ is turned off at $\mathrm{t}_{5}$, the primary current $i_{p}$ starts to discharge the capacitor $C_{D S}$. The voltage across $Q_{1}$ and $L_{M 1}$ is linearly decreasing and increasing, respectively. At $t_{6}, V_{D S}$ has decreased to the point $\left(V_{D S}=V_{i n}-V_{C}+N_{2} V_{O}-N_{l} V_{O}\right)$ where the diode $D_{1}$ is forward biased. Again, $D_{1}$ and $D_{2}$ conduct simuitaneously.

Stage $7\left(\mathrm{t}_{6} \sim \mathrm{t}_{7}\right):$ In this stage, $L_{l}$ and $C_{D S}$ resonate. The voltage $V_{D S}(t)$ and the primary current $i_{p}(t)$ are found as:

$$
\begin{aligned}
& i_{P}(t)=i_{b} \cdot \cos \left[\omega_{r}\left(t-t_{6}\right)\right] \\
& V_{D S}(t)=\left[V_{i n}-V_{C}+\left(N_{2}-N_{1}\right) V_{O}\right]+i_{b} \cdot Z_{r} \cdot \sin \left[\omega_{r}\left(t-t_{6}\right)\right]
\end{aligned}
$$

Assuming the energy stored in $L_{l}$ is larger than the energy stored in $C_{D S}, V_{D S}$ is going to be discharged to zero. The anti-parallel diode of $Q_{1}$ starts to conduct.

Stage $8\left(\mathrm{t}_{7} \sim \mathrm{t}_{8}\right)$ : It is the interval that switch $Q_{l}$ can be turned on under zero-voltage-switching condition. The primary current $i_{p}$ is ramped up due to the positive voltage $V_{i n}-V_{C}+\left(N_{2}-N_{1}\right) V_{O}$ applies to the leakage inductor. At $\mathrm{t}_{8}, i_{p}$ reaches $i_{m 2}, D_{2}$ turns off, and another switching cycle starts $\left(\mathrm{t}_{8}=\mathrm{t}_{0}\right)$.

\section{DC ANALYSIS}

The dc characteristics of the two-transformer asymmetrical half-bridge converter can be obtained in a simple method by ignoring the transition intervals. Therefore, only the stage 1 and stage 5 are investigated in dc analysis.

\section{$A$. The static voltage transfer ratio}

The static voltage transfer ratio (VTR) can be obtained by applying the equal-volt-seconds criterion to the two isolated transformers. The result can be formulated as:

$$
\frac{V_{O}}{V_{\text {in }}}=\frac{D(1-D)}{N_{1} D+N_{2}(1-D)}
$$

From (5), the maximum value of the static VTR $\left(M_{\max }\right)$ and duty cycle $\left(D_{\max }\right)$ can be obtained:

$$
\begin{aligned}
& M_{\max }=\frac{1}{\left(\sqrt{N_{1}}+\sqrt{N_{2}}\right)^{2}} \\
& D_{\max }=\frac{\sqrt{N_{2}}}{\left(\sqrt{N_{1}}+\sqrt{N_{2}}\right)}
\end{aligned}
$$

Fig. 4 shows the VTR curve as a function of the different turn ratios and duty cycle. Tuning the different turn ratios for transformer $T_{1}$ and $T_{2}$, the maximum allowable duty cycle can be adjusted, but the maximum value of VTR also affected. For example, if $\mathrm{N}_{2} / \mathrm{N}_{1}=1$, the $\mathrm{D}_{\max }=50 \%$ and $\mathrm{M}_{\max }=0.25$. Changing the turn ratio into $\mathrm{N}_{2} / \mathrm{N}_{1}=2, \mathrm{D}_{\max }$ can be augmented to $58.6 \%$, but $\mathrm{M}_{\max }$ decreased to 0.172 .

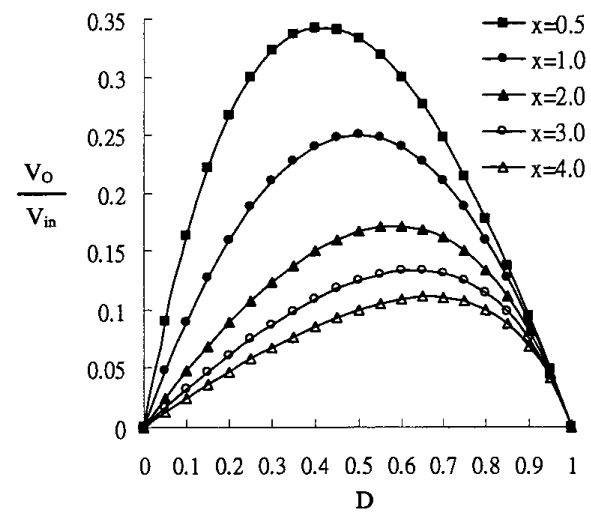

Fig. 4. Voltage transfer ratio for different turn ratios (where, $x=N_{2} / N_{1}$ is the different turn ratios coefficient)

\section{B. Output rectifier voltage stress}

Another advantage of modifying different turn ratios is balanced the reverse voltage stress of the output rectifier. The normalized reverse voltage in steady state across the output rectifiers can be calculated as follows:

$$
\begin{aligned}
& \frac{V_{D 1}(x)}{V_{o}}=\frac{1}{1-D_{\text {max }}(x)} \\
& \frac{V_{D 2}(x, k)}{V_{O}}=\frac{1}{D_{\min }(x, k)}
\end{aligned}
$$

where, $k=V_{\text {inmax }} / V_{\text {inmin }}$ is the input voltage range coefficient.

The value of $\mathrm{x}$ dominates the reverse voltage across $D_{1}$ and the reverse voltage across $D_{2}$ is a function of $x$ and $k$. Fig. 5 shows the normalized reverse voltage across the two output rectifiers with different $x$ and $k$. By augmenting the value of $x$, the reverse voltage across $D_{2}$ can be reduced. And it just increases the reverse voltage across $D_{1}$ slightly.

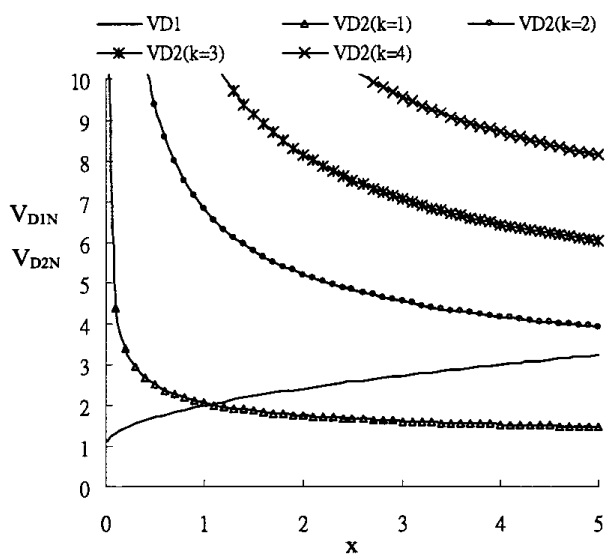

Fig. 5 Normalized reverse voltage across output rectifiers versus $x$ for different input voltage range 


\section{Maximum magnetizing current of the transformers}

When $Q_{I}$ is turned on, the magnetizing currents raise cause by the positive voltage applied to the magnetizing inductors. When $Q_{2}$ is turned on, these currents descend gradually. Taking the ac swing of the magnetizing current into account, the peak magnetizing current of $T_{l}\left(i_{m l}\right)$ and $T_{2}\left(i_{m 2}{ }^{+}\right)$are:

$$
\begin{aligned}
& i_{m 2}^{+}=\frac{I_{O} \cdot(1-D)}{N_{1} D+N_{2}(1-D)}+\frac{N_{2} V_{o}}{2 L_{m 2} f_{S}}(1-D) \\
& i_{m 1}^{-}=\frac{-I_{O} \cdot D}{N_{1} D+N_{2}(1-D)}-\frac{N_{1} V_{o}}{2 L_{m 1} f_{S}} D
\end{aligned}
$$

\section{Transformers Power Distribution}

The power distribution of the two transformers in one switching period can be described as the following equation

$$
\begin{aligned}
& P_{T 1}=\left(I_{m 2 D c}-I_{m 1 D C}\right) \cdot D \cdot N_{1} V_{o}=\frac{D}{x+D \cdot(1-x)} \cdot P_{O} \\
& P_{T 2}=\left(I_{m 2 D c}-I_{m 1 D C}\right) \cdot(1-D) \cdot N_{2} V_{O} \doteq \frac{x \cdot(1-D)}{x+D \cdot(1-x)} \cdot P_{O}
\end{aligned}
$$

Where $P_{T 1}$ and $P_{T 2}$ represents the power distribution of $T_{1}$ and $T_{2}$ in one switching period, respectively. Fig. 6 shows the power distribution ratio of the two transformers $\left(P_{T 1} / P_{T 2}\right)$ in one switching period with different turn ratios ( $x$ from 0.2 to 3 ) and duty cycle ( $D$ from 0.2 to 0.5 ). It is found that when the converter operates at the maximum duty cycle, the two transformers share the same power. The different turn ratios do not improve the uneven power distribution, but actually make it slightly worse.

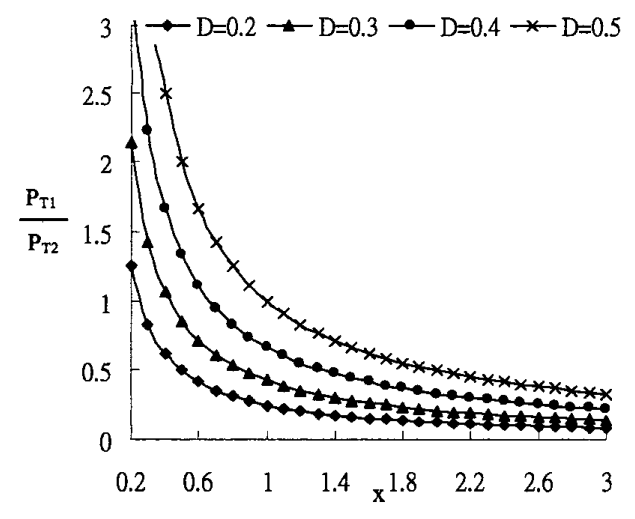

Fig. 6 The power distribution ratio of the transformers versus $x$ for different duty cycle.

\section{ZERO-VOLTAGE SWITCHING ANALYSIS}

As above-mentioned, there is a short transient interval between one MOSFET to be turned on and the other one has been turned off. Equations (2) and (4) represent the resonant behavior of the converter during the transition intervals. ZVS condition of the switch $Q_{2}$ and $Q_{1}$ can be derived from (2) and (4). In order to achieve ZVS, the energy stored in $L_{l}$ should be larger than the energy stored in $C_{D S}$. And it should satisfy the following equations.

$$
\begin{aligned}
& L_{l}\left|i_{p}\left(t_{2}\right)\right|^{2} \geq C_{D S}\left[V_{C}-\left(N_{2}-N_{1}\right) V_{O}\right]^{2} \\
& L_{l}\left|i_{p}\left(t_{6}\right)\right|^{2} \geq C_{D S}\left[V_{i n}-V_{C}+\left(N_{2}-N_{1}\right) V_{O}\right]^{2}
\end{aligned}
$$

Where $i_{p}\left(t_{2}\right)$ and $i_{p}\left(t_{6}\right)$ can be approximated to $i_{m 2}{ }^{+}$and $i_{m I}{ }^{-}$, respectively. Substituting (10) and (11) into (14) and (15), we can get:

$$
\begin{aligned}
& L_{l} \geq C_{D S} \frac{\left(N_{1} V_{O}\right)^{2}}{(1-D)^{4}} /\left[I_{r}+\frac{N_{2} V_{O}}{2 L_{m 2} f_{S}}\right]^{2} \\
& L_{l} \geq C_{D S} \frac{\left(N_{2} V_{O}\right)^{2}}{D^{4}} /\left[I_{r}+\frac{N_{1} V_{O}}{2 L_{m 1} f_{S}}\right]^{2} \\
& I_{r}=\frac{I_{O}}{N_{1} D+N_{2}(1-D)}
\end{aligned}
$$

Equations (16) and (17) formulate the minimum required value of the leakage inductance for reaching ZVS operation of the switches $Q_{2}$ and $Q_{1}$, respectively. Obviously, the critical ZVS condition of the $Q_{1}$ is stricter than $Q_{2}$. Therefore, the zero-voltage-switching of $Q_{l}$ should be drawn more attention in practical design. Moreover, a smaller magnetizing inductance is helpful to achieve ZVS operation of the switches.

\section{DESIGN PROCEDURE}

The design of significant circuit parameters can be derived from pondering over some design considerations. The procedure is described as follows.

\section{A. Select the different turn ratios}

In switching power supply, the conduction and switching loss of the output rectifier is the dominant loss component. In order to decrease these losses, the lower rating voltage rectifiers should be chosen such that a short recovery time and lower forward voltage drop diode can be used in practical application. Therefore, decreasing the reverse voltage across rectifiers is one of the most important trade offs for switching power supply design. In the modified asymmetrical half-bridge converter, the family of curves of normalized reverse voltage stress across the rectifiers with different input voltage range coefficient $(k)$ and different turn ratios coefficient $(x)$ has shown in Fig. 5. Base on the input voltage range and reverse voltage stress across the rectifiers, the different turn ratios can be selected. For example, if the input voltage range is unvaried $(k=I)$, the different turn ratios must be chosen as $x=1$. In this case, the rectifiers accept the same reverse voltage stress. If $k=2$, in order to balance the reverse voltage across the rectifiers, the most suitable different turn ratios should be chosen as $x=2$.

\section{$B$. Select the normal operation duty}

In modified asymmetrical half-bridge converter, it is a 
preferable choice to even the power distribution of the transformers for practical application. Fig. 6 shows the power distribution ratio of the two transformers with different turn ratios $(x)$ and duty cycle $(D)$. If the different turn ratios are chosen as $x=1$, the optimal design of the duty cycle is 0.5 . But in practical design, the real $D_{\max }$ should be smaller than theoretical value such that there is enough margins to respond to load disturbances or duty cycle loss.

\section{Select the transformer turn ratios}

If we neglect the leakage inductance, the primary and secondary duty cycle is quite close, and the turn ratios of $T_{1}$ $\left(N_{1}\right)$ can be determined from (5):

$$
N_{1}=\frac{D \cdot(1-D)}{[D+x \cdot(1-D)]} \cdot \frac{V_{\text {in }}}{V_{o}}
$$

When taking the duty loss into consideration, the calculated value by (26) is always smaller than the desired. The realistic value can get by adding two or three turns of the calculated value. The turn ratios of $T_{2}$ is set as: $N_{2}=N_{l} \cdot x$.

\section{Determine the magnetizing inductors}

The demands of the maximum flux density ( $B_{T 1, \max }$, $\left.B_{T 2, \max }\right)$ of the transformers can be calculated as:

$$
\begin{aligned}
B_{T 1, \max } & =\left[\frac{N_{1} V_{o} D}{2 W_{1} A_{e 1} f_{S}}+\frac{L_{m 1} D I_{r}}{W_{1} A_{e 1}}\right] \cdot 10^{8} \\
B_{T 2, \max } & =\left[\frac{N_{2} V_{o}(1-D)}{2 W_{3} A_{e 2} f_{S}}+\frac{L_{m 2}(1-D) I_{r}}{W_{3} A_{e 2}}\right] \cdot 10^{8}
\end{aligned}
$$

If the useable flux density of the material is $B_{\text {sat }}$, the maximum value of the magnetizing inductances can be derived from (20) and (21). And the magnetizing inductances should obey the following equations.

$$
\begin{aligned}
& L_{m 1} \leq\left[B_{s a t} \cdot 10^{-8}-\frac{N_{1} V_{o} D}{2 W_{1} A_{e 1} f_{S}}\right] A_{e 1} \cdot W_{1} / I_{r} D \\
& L_{m 2} \leq\left[B_{s a t} \cdot 10^{-8}-\frac{N_{2} V_{O}(1-D)}{2 W_{3} A_{e 2} f_{S}}\right] A_{e 2} \cdot W_{3} / I_{r}(1-D)
\end{aligned}
$$

\section{E. Design leakage inductance}

The ZVS condition of $S_{I}$ is quantized as Equation (17). Fig. 7 shows the required value of the leakage inductance with different output current and duty cycle of the studied converter. If the ZVS range is selected, the minimum value of the required leakage inductor can be calculated from (17). Either a larger leakage inductance or a smaller magnetizing inductance is helpful to achieve ZVS of $S_{l}$. If there is enough margins to respond to load disturbances or duty cycle loss, the leakage inductance should choose a larger value.

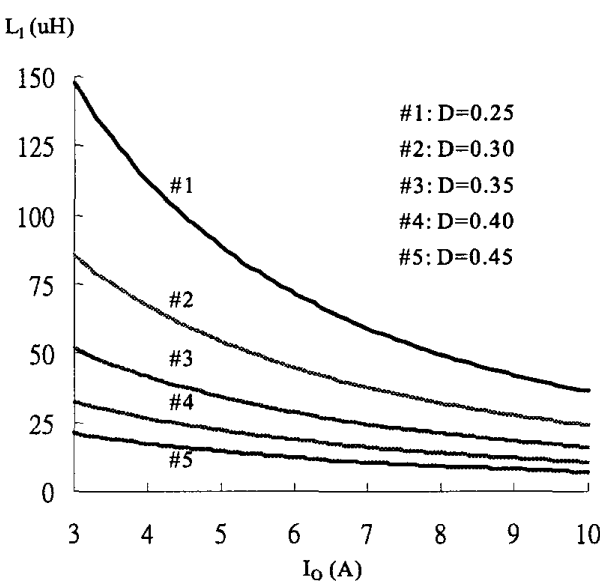

Fig. 7 Required leakage inductance for different range ZVS operation of $S_{1}$

\section{EXPERIMENTAL RESULTS}

In order to characterize the soft switching phenomena of the modified asymmetrical half-bridge converter, a prototype was constructed to the specifications listed below:

input voltage: $400 \mathrm{VDC}$; output voltage: $24 \mathrm{VDC}$; maximum load current: $10 \mathrm{~A}$; switching frequency: 200 $\mathrm{kHz}$; normal operation duty cycle: 0.25 ; ZVS range: $80 \%$ to $100 \%$ load

Using the above-mentioned design procedure, the experimental converter was constructed using the following components:

- power switches $Q_{1}$ and $Q_{2}$ : Toshiba, 2SK2915;

- transformers $T_{I}: A_{e l}$ of core: $1 \mathrm{~cm}^{2} ; W_{l}: 25$ turns of $50 \times 0.1 \mathrm{~mm} ; W_{2}: 8$ turns of Litz wire $50 \times 0.1 \mathrm{~mm} \times 3 ; L_{M l}: 150$ $\mathrm{uH}$;

- transformer $T_{2}: A_{e 2}$ of core: $1 \mathrm{~cm}^{2} ; W_{3}: 25$ turns of $50 \times 0.1 \mathrm{~mm} ; W_{4}: 8$ turns of Litz wire $50 \times 0.1 \mathrm{~mm} \times 3 ; L_{M 2}: 150$ $\mathrm{uH}$;

- output rectifiers $D_{3}$ and $D_{4}$ : NIEC, C25P20F (FRD, $\mathrm{V}_{\mathrm{F}}=0.98 \mathrm{~V}$ );

- leakage inductance $L_{l}: 10 \mathrm{uH}$.

Under full load operation, the experimental waveforms on the key components are shown in Fig. 8. It is clear that ZVS operation of $Q_{1}$ is achieved because the device is turned on after the voltage across it falls to zero. In additional, the experimental result is in a good agreement with the theoretical analysis, as sown in Fig. 3.

The overall efficiency was measured under the different output current range, as shown in Fig. 9. The efficiency remains above $90 \%$ from $50 \%$ to full load. 


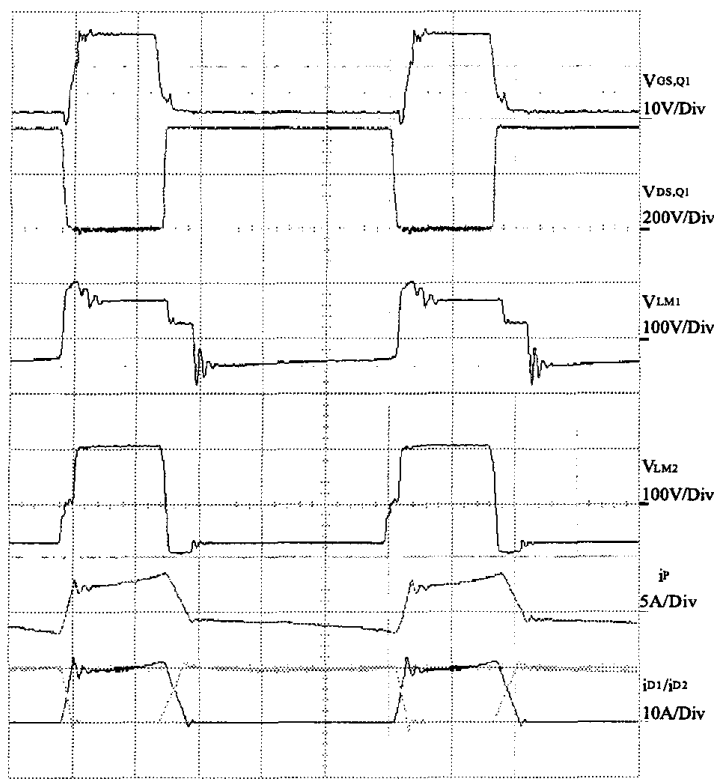

Fig. 8 Experimental waveforms on key components. (Time scale is 1 us/div).

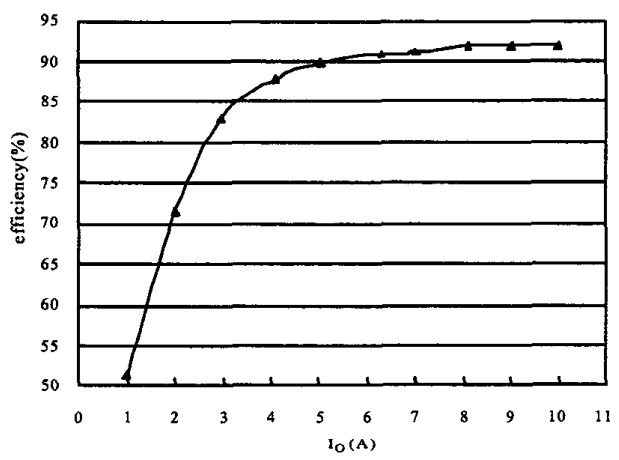

Fig. 9 Measured efficiency under different output current.

\section{CONCLUSION}

The operational principles and DC characteristics have been analyzed for the two-transformer asymmetrical half-bridge converter. The results obtained by theoretical analysis can be utilized to quantize the ZVS condition of the power switches and predict the performance of the converter. The critical ZVS condition of $Q_{l}$ is stricter than $Q_{2}$. In practical application, it is necessary to add an external inductor for achieving ZVS operation of $Q_{I}$. Taking some practical trade-offs such as rectifier stress, ZVS operation, transformer power distribution etc into considerations, the design procedure is developed. According to the design rules, a prototype converter has been built. The experimental result is in a good agreement with the theoretical derivations.

\section{REFERENCE}

[1]. C. P. Henze, D. S. Lo, J. Martin, and C. Hubert, "Zero-voltage resonant transition switching power converter," U.S. Patent 5 057986 , Oct. 1991.

[2]. P. Imbertson and N. Mohan, "Asymmetrical Duty Cycle Permits Zero Switching Loss in PWM Circuits with No Conduction Loss Penalty," IEEE Trans. Industry Applications, Vol.29, No.1, Jan./Feb. 1993, pp. 121-125.

[3]. S. Korotkov, V. Meleshin, R. Miftahutdinov and S. Fraidlin, "Soft-Switched Asymmetrical Half-bridge DC/DC Converter: Steady-State Analysis: An Analysis Of Switching Processes," TELESCON, 1997, pp. 177-184.

[4]. R. Oruganti, P. C. Heng, J. T. K. Guan, and L. A Choy, "Soft-Switched DC/DC Converter with PWM Control," IEEE Trans. Power Electronics, Vol. 13, No. 1, Jan. 1998, pp. 102-114.

[5]. R. Miftakhutdinov, A. Nemchinov, V. Meleshin and S. Fraidlin," Modified Asymmetrical ZVS Half-Bridge DC-DC Converter," Applied Power Electronics Conference and Exposition, 1999, pp. 567-574.

[6]. W. Chen, P. Xu and Fred C. Lee, 'The Optimization of Asymmetrical Half Bridge Converter," Applied Power Electronics Conference and Exposition, 2001, pp. 703-707. 